\title{
FABRICAÇÃO DE QUEIJO PETIT SUISSE POR ULTRAFILTRAÇÃO DE LEITE COAGULADO. EFEITO DO TRATAMENTO TÉRMICO DO LEITE NO DESEMPENHO DA MEMBRANA ${ }^{1}$
}

\author{
Pricila Grego VEIGA², Walkiria Hanada VIOTTO2,*
}

\begin{abstract}
RESUMO
Leite desnatado coagulado foi ultrafiltrado em membrana tubular cerâmica de $0,08 \mu \mathrm{m}$ com objetivo de avaliar a influência de diferentes tratamentos térmicos do leite sobre o fluxo, o coeficiente de retenção protéico, o coeficiente de retenção de cálcio e o rendimento protéico no processamento de queijo petit suisse. Os tratamentos térmicos utilizados foram $85^{\circ} \mathrm{C} / 30 \mathrm{~min}$ e $72^{\circ} \mathrm{C} / 15 \mathrm{seg}$. $O$ efeito do tratamento térmico não foi significativo $(p<0,05)$ na retenção de proteína e cálcio, e no rendimento protéico. Houve aumento significativo do fluxo de permeado durante a ultrafiltração do leite coagulado quando o leite foi submetido ao tratamento térmico menos intenso $\left(72^{\circ} \mathrm{C} / 15 \mathrm{seg}\right)$. O tratamento térmico mais intenso pode ter resultado em uma maior atração entre as micelas de caseína e, entre micelas e a superfície da membrana, aumentando a adsorção das proteínas à superfície da membrana, conseqüentemente reduzindo o fluxo de permeado. Também pode ter ocorrido entupimento dos poros da membrana por $\alpha$-lactoalbumina e $\beta$-lactoglobulina desnaturadas, agravando o "fouling".
\end{abstract}

Palavras-chave: ultrafiltração; tratamento térmico; queijo petit suisse; fluxo de permeado.

\section{SUMMARY}

PETIT SUISSE CHEESE PRODUCED BY ULTRAFILTRATION OF COAGULATED MILK. Coagulated skim milk was ultrafiltered in ceramic tubular membrane with cut off $0.08 \mu \mathrm{m}$ with the objective of evaluating the influence of different milk heat treatments on permeate flux, on protein retention coefficient, on calcium retention coefficient and on protein yield during the petit suisse cheese process. Heat treatment of milk was $85^{\circ} \mathrm{C} / 30 \mathrm{~min}$ and $72^{\circ} \mathrm{C} / 15 \mathrm{sec}$. No differences in the retention of protein and calcium, nor in the protein yield due to heat treatment of milk, were observed. A significant increase in permeate flux was observed when the milk was heated to $72^{\circ} \mathrm{C} / 15 \mathrm{sec}$. The most intense heat treatment could result in a higher attraction between the casein micelles and between the micelles and the membrane surface, increasing the protein adsorption on the membrane surface and, consequently, reducing the permeate flux. Denaturated $\alpha$-lactoalbumin and $\beta$-lactoglobulin may have plugged the membrane pores, which would also help to increase fouling.

Keywords: ultrafiltration; heat treatment; petit suisse cheese; permeate flux.

\section{1 - INTRODUÇÃO}

No Brasil, a fabricação de queijo petit suisse utiliza centrífuga para efetuar o processo de separação da massa, produzindo o queijo quark, que é a base utilizada, juntamente com açúcar, creme e frutas, para produzir o petit suisse. O uso de ultrafiltração na produção

${ }_{1}^{1}$ Recebido para publicação em 20/10/99. Aceito para publicação em 19/09/01.

${ }^{2}$ Faculdade de Engenharia de Alimentos, Universidade Estadual de Campinas - UNICAMP. CEP 13083-970 - Campinas-SP, Brasil.E-mail:walkiria@fea.unicamp.br.

${ }^{*}$ A quem a correspondência deve ser enviada. de queijos quark é uma prática já utilizada em outros países por resultar em economia de energia, melhor rendimento e maior valor nutritivo.

O principal problema tecnológico do quark, produzido pela ultrafiltração do leite, reside no alto teor de cálcio, que acarreta mudanças nas características sensoriais do queijo [22, 26]. A ultrafiltração de leite coagulado para produção de quark é uma alternativa para a redução do teor de cálcio no retentado, já que com a fermentação, o cálcio é removido da micela de caseína para a fase aquosa, podendo melhorar a textura e possivelmente minimizar o defeito de sabor amargo no queijo.

O fluxo do permeado é a variável crítica na determinação e eficiência do processo de ultrafiltração, sendo a formação da camada gel polarizada e o "fouling", os responsáveis pela redução na taxa de permeação da membrana [5, 12, 15, 24]. Proteínas e minerais, especialmente cálcio e fósforo, têm sido identificados como agentes do "fouling" durante a ultrafiltração de leite [11, $16,27,28]$.

Tratamentos térmicos podem ser efetuados para reduzir o efeito de minerais, precipitando o excesso de sais de fosfato de cálcio e reduzindo o cálcio iônico no líquido de alimentação, o que leva à diminuição do "fouling" e, conseqüentemente, ao aumento da taxa de permeação [23]. Durante o aquecimento, as proteínas também são afetadas. A $\alpha$-lactoalbumina e a $\beta$ lactoglobulina são desnaturadas e se associam à micela de caseína [6, 18, 19]. Essa associação ocorre inicialmente por interações hidrofóbicas e posteriormente por ligações dissulfídicas com a א-caseína [9]. Um tratamento térmico mais intenso do leite, por exemplo, a $85^{\circ} \mathrm{C} / 30 \mathrm{~min}$, resulta em maior interação entre proteínas do soro e caseína quando comparado a leite tratado a temperaturas como $75^{\circ} \mathrm{C}$ por menos de 20 minutos [10], o que pode afetar o desempenho da membrana.

$\mathrm{O} \mathrm{pH}$, aliado ao tratamento térmico, também exerce influência sobre as micelas de caseína. Em leites submetidos a tratamentos térmicos intensos, a pH 5,4, micelas de diâmetro de 100-250nm são predominantes. No $\mathrm{pH} 5,1$, parece haver desintegração parcial da micela em subpartículas (30-40nm) e, a pH 4,8, as micelas constituem grandes agregados de tamanhos não específicos [20]. Durante a fermentação, as micelas de caseína tendem a se fundir, levando à formação de uma rede densa. Entretanto, o processo de fusão parece ser inibido pela presença de interações na superfície da micela [18], sugerindo que tratamentos térmicos mais intensos resultem em maiores agregados, mesmo após a fermentação, o que poderia resultar em uma permeação diferente do fluido de alimentação. 
Este trabalho teve como objetivo avaliar a influência do tratamento térmico do leite no fluxo de permeado, coeficiente de retenção protéica da membrana, coeficiente de retenção de cálcio e no rendimento protéico do queijo petit suisse obtido por ultrafiltração de leite coagulado.

\section{2 - MATERIAIS E MÉTODOS}

\section{1 - Matérias-primas}

Foram utilizados leite desnatado e creme de leite (70\% de gordura), provenientes da Cooperativa do Produtor de Leite da Região de Campinas; cultura láctica homofermentativa, composta por múltiplas cepas mistas de Lactococcus lactis ssp cremoris e Lactococcus lactis ssp lactis, (marca EZAL $®$, série MA, fornecida pela RHODIA); açúcar, e polpa de morango "starpolpa de morango lat", sem semente, fornecida pela KERRY do Brasil Ltda.

\section{2 - Coleta e amostragem}

Leite, coalhada e permeado foram coletados e amostrados segundo metodologia da AOAC 33.02.02 [1], e a massa básica e o petit suisse, segundo AOAC 33.07.02 [1]. As etapas do processamento onde foram retiradas as amostras para análises de composição estão indicadas no fluxograma da Figura 1. A polpa de morango foi devidamente misturada, embalada em papel laminado com barreira à passagem de luz e gases, em pacotes de $500 \mathrm{~g}$ e congelada até ser utilizada como ingrediente do petit suisse.

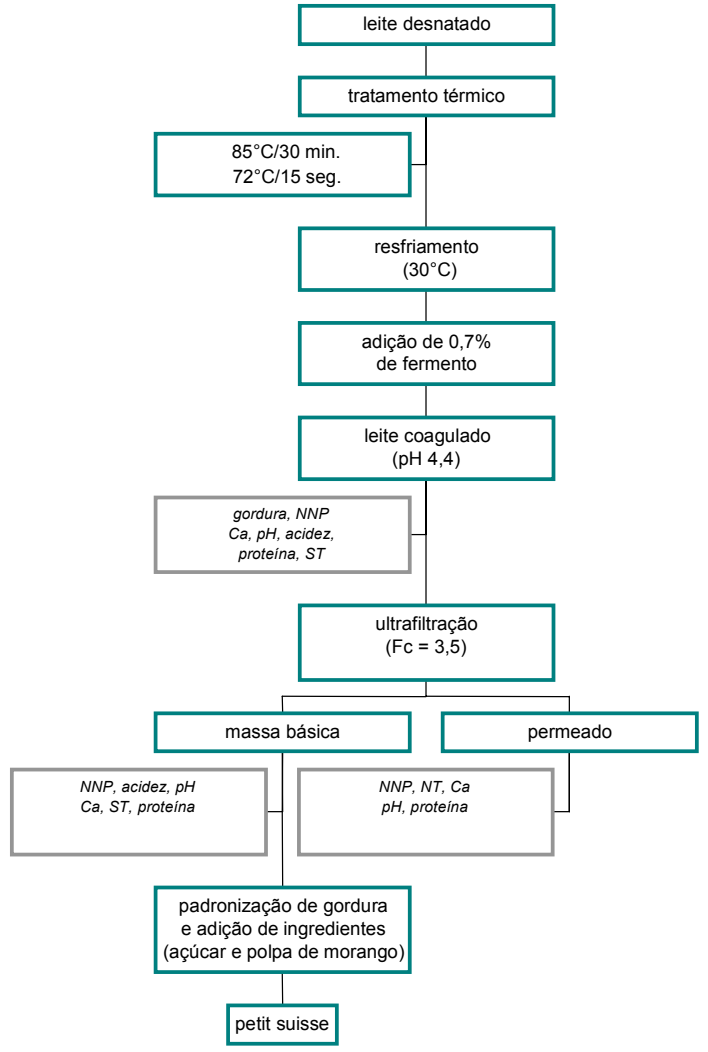

FIGURA 1. Fluxograma de processo e amostragem.

\section{3 - Processo de fabricação do queijo petit suisse por ultrafiltração}

Foram empregados dois diferentes tratamentos térmicos no leite desnatado para a fabricação de queijo petit suisse por ultrafiltração de leite coagulado. Os processamentos foram efetuados em duplicata, resultando em quatro experimentos. Leite desnatado foi tratado termicamente, em tanque encamisado, a $85^{\circ} \mathrm{C} / 30 \mathrm{~min}$ ou pasteurizado em trocador de calor a placas a $72^{\circ} \mathrm{C} / 15 \mathrm{seg}$. Depois de resfriado a $30^{\circ} \mathrm{C}$, o leite foi inoculado com $0,7 \%$ de cultura láctica mesófila (mistura de Lactococcus lactis ssp cremoris e Lactococcus lactis ssp lactis), e deixado a fermentar durante a noite, até atingir o $\mathrm{pH}$ de 4,4 . $60 \mathrm{~kg}$ da coalhada resultante foram quebradas com agitador e ultrafiltradas até fator de concentração à temperatura média de $35^{\circ} \mathrm{C}$, até o fator de concentração 3,5 , com pressão interna de $1,00 \mathrm{~kg} / \mathrm{cm}^{2}$ e pressão externa aproximadamente igual à ambiente. A massa básica obtida (queijo quark) foi padronizada para $5,8 \%$ de gordura, fixando-se o teor de açúcar em $11 \%$ e o teor de polpa de fruta em $7 \%$. A Figura 1 mostra o fluxograma de fabricação e as análises realizadas para o leite coagulado, a massa básica ou retentado, e o permeado.

\section{4 - Planta-piloto de ultrafiltração}

Para este experimento foi utilizada a planta-piloto de ultrafiltração mostrada na Figura 2. Foi utilizado também o cartucho de ultrafiltração da marca CARBOSEP, modelo M 6, tipo tubular, com poro médio de corte de $0,08 \mu \mathrm{m}$ e suporte poroso de carbono, recoberta por uma camada de óxido de zircônio com película de $30 \mu \mathrm{m}$, com área de permeação de $1,67 \mathrm{~m}^{2}$, com 37 tubos de membrana $(1,2 \mathrm{~m}$ de comprimento e $6 \mathrm{~mm}$ de diâmetro interno).

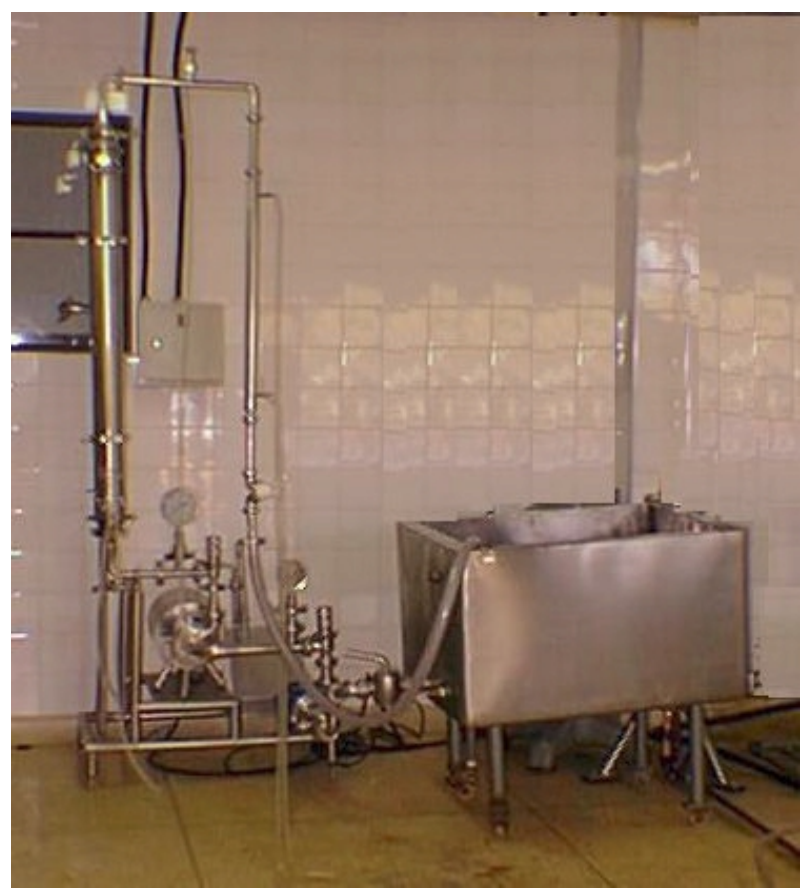

FIGURA 2. Planta-piloto de ultrafiltração. 


\section{5 - Desempenho da membrana de ultrafiltração}

O desempenho da membrana de ultrafiltração foi medido pelo declínio da taxa de permeação durante a ultrafiltração, pelo coeficiente de retenção de proteína e do cálcio [7] e pelo rendimento protéico [14].

\subsection{1 - Fluxo de permeado (kg/h.m²)}

Curvas de permeação foram construídas para avaliar a evolução do fluxo de permeado durante a UF. O fluxo de permeado foi medido em função do tempo de processamento. O tempo de ultrafiltração foi medido com um cronômetro e o permeado retirado, coletado em recipiente durante intervalo de tempo previamente determinado e pesado em balança digital com capacidade para $10 \mathrm{~kg}$ e precisão de $0,002 \mathrm{~kg}$. O fluxo médio de permeado foi então calculado dividindo-se o peso de permeado pelo tempo e área da membrana.

\subsection{2 - Coeficiente de retenção de proteína e cálcio}

O coeficiente de retenção de um determinado componente é a medida quantitativa da capacidade da membrana em reter esse componente. Os valores de retenção da membrana para cada substância podem ser determinados pela análise de amostras do permeado e do fluido de alimentação. A maioria dos trabalhos científicos que versam sobre ultrafiltração utilizam a equação

$\operatorname{Re}=1-\frac{Y p}{Y r}$

para determinar a retenção de um determinado componente:

onde:

$\mathrm{Re}=$ coeficiente de retenção do componente;

$Y p=\%$ do componente $Y$ no permeado;

$\mathrm{Yr}=\%$ do componente $\mathrm{Y}$ no retentado.

Entretanto, essa equação não considera que a concentração ocorre somente pela remoção da fase aquosa, podendo resultar em valores de retenção negativos, significando que componentes com retenções negativas passam pela membrana mais rapidamente que a água. Glover citado por BASTIAN, COLLINGE, ERNESTON [4] sugeriu que o coeficiente de retenção para moléculas parcialmente retidas seja expresso com base na fase aquosa, como porcentagem da fase aquosa do retentado:

$Y$ na solução $=100 \cdot \frac{Y}{\% \text { água }+Y}$

onde: $\mathrm{Y}=\%$ de um determinado componente no retentado ou permeado.

Substituindo a equação (2) em (1), tem-se uma equação para determinar a retenção de componentes parcialmente retidos, como o cálcio:

$$
R=1-\frac{(Y p)\left(\% \text { água }_{p}+Y p\right)}{(Y r)\left(\% \text { água }_{r}+Y r\right)}
$$

A retenção de proteína foi calculada pela equação (1) e a retenção de cálcio, pela equação (3).

\subsection{3 - Fator de concentração (Fc)}

O fator de concentração foi calculado segundo a equação (4):

$$
F_{c}=\frac{\text { peso do leite coagulado }}{\text { peso do retentado }}
$$

Onde: peso retentado $=$ peso leite coagulado inicial peso permeado

\subsection{4 - Rendimento protéico $\left(\operatorname{Re}_{\mathrm{p}}\right)$}

O rendimento protéico foi calculado pela equação (5):

$R e_{p}=F c^{R-1}$

Onde $\mathrm{Re}$ = rendimento protéico;

$\mathrm{Fc}=$ fator de concentração;

$\mathrm{R}=$ coeficiente de retenção da membrana.

\section{6 - Limpeza e sanificação da unidade de UF}

Uma pré-limpeza foi efetuada após cada processamento, seguindo a seqüência: 1) enxágüe com água deionizada, 2) limpeza com solução de detergente enzimático $3 \%$, da marca Heynkel, à temperatura ambiente, por 30 minutos, 3) imersão em solução de detergente enzimático $3 \%$, à temperatura ambiente. 0 procedimento de limpeza foi o seguinte: 1) enxágüe com água deionizada, 2) limpeza com solução de hidróxido de sódio $1 \%$, a $70^{\circ} \mathrm{C}$, por $\left.30 \mathrm{~min}, 3\right)$ enxágüe com água deionizada até neutralização, 4) lavagem com solução de ácido nítrico $0,35 \%$, a $50^{\circ} \mathrm{C}$, por $30 \mathrm{~min}$, 5) enxágüe com água deionizada até neutralização. Após a limpeza, o fluxo de água pura foi medido a $25^{\circ} \mathrm{C}$ para avaliar a eficiência da limpeza e, quando o fluxo foi inferior ao fluxo inicial, o processo de limpeza foi repetido. Antes de cada processamento, a membrana foi sanitizada, seguindo a seqüência: 1) enxágüe com água deionizada, 2) limpeza com solução de hipoclorito de sódio 200 ppm, à temperatura ambiente, por 30 minutos, 3) enxágüe com água deionizada até $\mathrm{pH}$ neutro e desaparecimento do cheiro de cloro. O fluxo de água pura foi medido a $25^{\circ} \mathrm{C}$.

\section{7 - Análises físico-químicas do leite coagulado, permeado e massa básica}

O teor de sólidos totais do leite coagulado, massa básica e permeado foi determinado gravimetricamente, em estufa a $105^{\circ} \mathrm{C}$ [13]. Todas as determinações de nitrogênio foram feitas por Kjeldahl. As porcentagens de nitrogênio das análises de nitrogênio total e do nitrogênio não-protéico foram multiplicadas por 6,38, para dar o equivalente em proteínas e determinadas para o leite coagulado e o permeado (AOAC 33.07.12 e 33.07.13) [1], e para a massa básica (AOAC 33.01.12 e 33.01.13) [1]. O teor de gordura do leite coagulado e da massa básica foi determinado por Gerber [3]. Amostras de leite coagulado, massa básica e permeado foram analisadas quanto ao teor de cálcio, pelo método da dureza parcial em água, através de digestão úmida da amostra, seguida de titulação com EDTA, na presença de 
indicador murexida (AOAC 11.1.21) [2]. As amostras também foram analisadas quanto à acidez titulável do leite coagulado, permeado [3] e massa básica (AOAC 33.07.14) [1] e quanto ao $\mathrm{pH}$ [3].

\section{8 - Análise estatística}

O coeficiente de retenção de proteína, coeficiente de retenção de cálcio, teor de proteína total, nitrogênio não-protéico, proteína e o teor de cálcio foram tratados estatisticamente pela análise de variância (ANOVA) e pelo teste de Tuckey [17]. Amostras que não apresentaram diferenças significativas $(p<0,05)$ entre os diferentes tratamentos térmicos $\left(85^{\circ} \mathrm{C} / 30\right.$ min e $\left.72^{\circ} \mathrm{C} / 15 \mathrm{seg}\right)$ foram identificadas com a mesma letra.

\section{3 - RESULTADOS E DISCUSSÃO}

\section{1 - Efeito do tratamento térmico do leite no fluxo de permeado}

A Tabela 1 mostra o efeito do tratamento térmico do leite sobre o fluxo de permeado em função do fator de concentração (por interpolação ou extrapolação linear, para efeito de comparação).

O tratamento térmico do leite influenciou o fluxo de permeado, que diminuiu com o aumento da intensidade do tratamento térmico. A Figura 3 apresenta o fluxo de permeado em função do tempo de processo para os diferentes tratamentos térmicos do leite e a Figura 4 apresenta o fluxo de permeado em função do fator de concentração. É visível (Figuras 3 e 4) que quando o leite foi submetido ao tratamento mais intenso de $85^{\circ} \mathrm{C} / 30 \mathrm{~min}$, o tempo necessário para se atingir o fator de concentração 3,5 passou de uma média de oito horas e meia para cerca de duas horas, quando se tratou o leite a $72^{\circ} \mathrm{C} / 15 \mathrm{seg}$.

TABELA 1. Efeito do tratamento térmico do leite $\left(85^{\circ} \mathrm{C} / 30 \mathrm{~min}\right.$ e $72^{\circ} \mathrm{C} / 15$ seg.) sobre o fluxo de permeado em função do fator de concentração.

\begin{tabular}{ccc}
\hline $\begin{array}{c}\text { Fator de } \\
\text { Concentração }\end{array}$ & $\begin{array}{c}\mathbf{8 5}^{\circ} \mathbf{C} / \mathbf{3 0 m i n} \\
\text { Fluxo permeado } \\
\left(\mathrm{kg} / \mathrm{h} \cdot \mathrm{m}^{2}\right)\end{array}$ & $\begin{array}{c}\mathbf{7 2}^{\mathbf{}} \mathbf{C} / \mathbf{1 5} \mathbf{s e g} \\
\left(\mathrm{kg} / \mathrm{h} \cdot \mathbf{m}^{2}\right)\end{array}$ \\
\hline 1,5 & 8,81 & 13,86 \\
2,0 & 7,06 & 11,29 \\
2,5 & 5,51 & 10,02 \\
3,0 & 4,12 & 9,84 \\
3,5 & 3,34 & 9,73 \\
\hline
\end{tabular}

A acumulação de solutos na superfície da membrana formando uma camada gel polarizada e posteriormente o "fouling" são considerados os fatores responsáveis pela redução do fluxo no permeado $[5,12$, $16,25]$. Os dois mecanismos principais na formação do "fouling" em ultrafiltração de leite são a adsorção de proteínas e a cristalização de sais de cálcio [27].

O baixo $\mathrm{pH}$ do leite coagulado $(4,4)$ torna improvável que o "fouling" seja resultado da cristalização dos sais de cálcio, portanto a redução no fluxo de permea- do com o tratamento térmico mais intenso provavelmente deveu-se a um aumento da adsorção de proteínas e/ou entupimento dos poros da membrana.

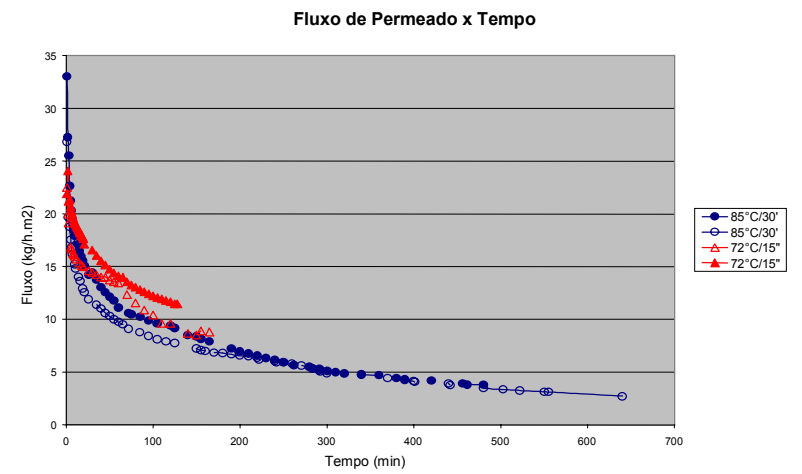

FIGURA 3. Efeito do tratamento térmico do leite $\left(85^{\circ} \mathrm{C} / 30 \mathrm{~min}\right.$ e $72^{\circ} \mathrm{C} / 15 \mathrm{seg}$ ) sobre o fluxo de permeado em função do tempo.

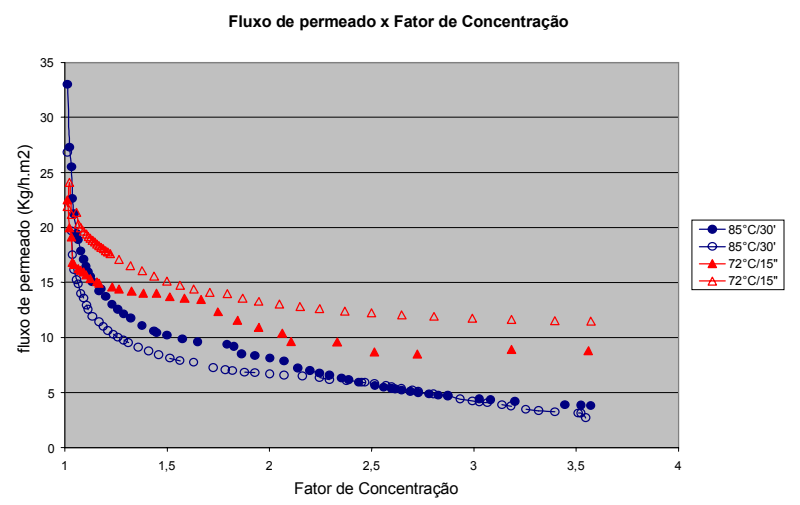

FIGURA 4. Efeito do tratamento térmico do leite $\left(85^{\circ} \mathrm{C} / 30 \mathrm{~min}\right.$ e $72^{\circ} \mathrm{C} / 15$ seg) sobre o fluxo de permeado em função do fator de concentração.

O aumento no tamanho da micela de caseína [8] e o aumento da hidrofobicidade [18] induzidos pelo tratamento térmico do leite poderiam ter resultado em uma maior atração entre as micelas de caseína e entre micelas e a superfície da membrana, aumentando a adsorção das proteínas à superfície da membrana e reduzindo o fluxo de permeado.

De acordo com MARSHALL, DAUFIN [16], a $\alpha-$ lactoalbumina e a $\beta$-lactoglobulina podem ser adsorvidas no interior dos poros. A desnaturação destas proteínas pelo tratamento térmico mais intenso do leite e a utilização de uma membrana de poro médio de $80 \mathrm{~nm}$ podem também ter resultado em entupimento dos poros da membrana, agravando o "fouling".

\section{2 - Coeficiente de retenção de proteína $\left(R_{p}\right)$ e cálcio $\left(\mathbf{R}_{\mathrm{c}}\right)$ :}

A Tabela 2 mostra o efeito do tratamento térmico do leite $\left(85^{\circ} \mathrm{C} / 30 \mathrm{~min}\right.$ e $\left.72^{\circ} \mathrm{C} / 15 \mathrm{seg}\right)$ nos teores de proteína e nitrogênio não-protéico do leite fermentado, massa básica, permeado e queijo petit suisse e, no teor de cálcio do leite fermentado, permeado e massa básica. 
Pode ser observado que o tratamento térmico do leite não influenciou significativamente $(p>0,05)$ o teor de proteína, nitrogênio não-protéico e cálcio total dos produtos.

TABELA 2. Efeito do tratamento térmico do leite $\left(85^{\circ} \mathrm{C} / 30 \mathrm{~min}\right.$ e $72^{\circ} \mathrm{C} / 15 \mathrm{seg}$ ) no teor de proteína e de nitrogênio não-protéico do leite fermentado, permeado, massa básica e queijo petit suisse (média de duas repetições).

\begin{tabular}{|c|c|c|c|c|c|c|}
\hline & \multicolumn{3}{|c|}{$85^{\circ} \mathrm{C} / 30 \mathrm{~min}$} & \multicolumn{3}{|c|}{$72^{\circ} \mathrm{C} / 15 \mathrm{seg}$} \\
\hline & NNP (\%) & Proteína (\%) & Cálcio (\%) & NNP (\%) & Proteína (\%) & Cálcio (\%) \\
\hline Leite coagulado & 0,03 & 3,11 & 0,07 & 0,03 & 3,27 & 0,07 \\
\hline Permeado & 0,02 & 0,44 & 0,06 & 0,02 & 0,44 & 0,06 \\
\hline Massa básica & 0,34 & 12,03 & 0,04 & 0,30 & 12,37 & 0,04 \\
\hline Petit suisse & 0,29 & 8,95 & - & 0,28 & 9,02 & - \\
\hline
\end{tabular}

Não houve diferença significativa $(p>0,05)$ entre as amostras.

A Tabela 3 mostra o efeito do tratamento térmico do leite sobre o coeficiente de retenção de proteína e cálcio durante a ultrafiltração.

TABELA 3. Efeito do tratamento térmico do leite $\left(85^{\circ} \mathrm{C} / 30 \mathrm{~min}\right.$ e $72^{\circ} \mathrm{C} / 15 \mathrm{seg}$ ) sobre o coeficiente de retenção de proteína, nitrogênio não-protéico e cálcio ultrafiltração.

\begin{tabular}{lcc}
\hline & $85^{\circ} \mathrm{C} / 30 \mathrm{~min}$ & $72^{\circ} \mathrm{C} / 15 \mathrm{seg}$ \\
\hline Retenção de proteína & 0,96 & 0,96 \\
Retenção de NNP & 0,94 & 0,93 \\
Retenção de cálcio & 0,63 & 0,65 \\
\hline
\end{tabular}

Não houve diferença significativa $(p>0,05)$ entre as amostras.

Os resultados da Tabela 3 mostram que a retenção de proteína e cálcio não foram afetadas pela mudança na intensidade do tratamento térmico do leite.

Embora o tratamento térmico mais intenso acarrete em redução do cálcio iônico, devido à conversão de fosfato de cálcio ao estado coloidal [21], os resultados indicaram que durante a fermentação pode ter ocorrido reconversão do cálcio coloidal em cálcio iônico, anulando as alterações causadas no cálcio, pelo tratamento de $85^{\circ} \mathrm{C} / 30 \mathrm{~min}$. Ou melhor, em relação ao estado do cálcio, quaisquer efeitos dos tratamentos térmicos empregados foram anulados pela posterior fermentação do leite. Além disso, o fato de não ter sido observada diferença significativa $(p>0,05)$ na retenção de cálcio total, para nenhum dos tratamentos térmicos empregados neste estudo, indica que as diferenças observadas no fluxo de permeado não foram causadas pelo cálcio.

Pelas Tabelas 2 e 3 pode ser observado um teor elevado de cálcio no permeado. MAHAUT et al. [15], que foram pioneiros na fabricação de queijos frescos por ultrafiltração de leite coagulado, também obtiveram valores semelhantes. A elevada permeação do cálcio era esperada, uma vez que o $\mathrm{pH}$ do leite coagulado foi de 4,4, próximo ao ponto isoelétrico. PATEL, REUTER, PROKOPEC [22] explicam que $60 \%$ do cálcio no leite está ligado à caseína e abaixando-se o pH (através de fermentação) tem-se a remoção do cálcio da micela para a fase aquosa e que no ponto isoelétrico do leite, praticamente não existe cálcio micelar. Nas condições estudadas, o cálcio estaria, portanto, livre em solução, o que acarretaria uma maior permeação pela membrana, quando comparada à permeação deste íon em leite não coagulado.

\section{3 - Rendimento protéico $\left(\operatorname{Re}_{\mathrm{p}}\right)$}

A Tabela 4 mostra o efeito do tratamento térmico do leite $\left(85^{\circ} \mathrm{C} / 30 \mathrm{~min}\right.$ e $\left.72^{\circ} \mathrm{C} / 15 \mathrm{seg}\right)$ sobre o rendimento de proteína durante a ultrafiltração, indicando que os tratamentos utilizados neste estudo não tiveram influência sobre o rendimento de proteína.

TABELA 4. Efeito do tratamento térmico $\left(85^{\circ} \mathrm{C} / 30\right.$ min e $72^{\circ} \mathrm{C} /$ $15 \mathrm{seg})$ do leite sobre o rendimento de proteína durante a ultrafiltração.

\begin{tabular}{ccc}
\hline & $\mathbf{8 5}^{\circ} \mathrm{C} / \mathbf{3 0} \mathbf{~ m i n}$ & $\mathbf{7 2}^{\circ} \mathrm{C} / \mathbf{1 5} \mathbf{~ s e g}$ \\
\hline Rendimento de proteína & 0,95 & 0,95 \\
\hline
\end{tabular}

Não houve diferença significativa $(p>0,05)$ entre as amostras.

\section{4 - CONCLUSÕES}

$\mathrm{O}$ tratamento térmico intenso do leite resultou em uma diminuição no fluxo de permeado, aumentando, conseqüentemente, o tempo de ultrafiltração em aproximadamente seis horas, para uma batelada de $60 \mathrm{~kg}$ de coalhada, quando comparado ao submetido ao tratamento térmico menos intenso, para uma mesma quantidade de coalhada. O tratamento térmico mais intenso pode ter resultado em uma maior atração entre as micelas de caseína e entre micelas e a superfície da membrana, aumentando a adsorção das proteínas à superfície da membrana e, conseqüentemente, reduzindo o fluxo de permeado. Também pode ter ocorrido entupimento dos poros da membrana pela $\alpha$-lactoalbumina e $\beta$ lactoglobulina desnaturadas, o que teria agravado o "fouling". Como não houve influência significativa $(p>0,05)$ do tratamento térmico sobre o rendimento de proteína, a utilização do tratamento térmico menos intenso seria recomendada, uma vez que diminuiria o tempo de ultrafiltração, com conseqüente redução nos custos do processamento.

\section{5 - REFERÊNCIAS BIBLIOGRÁFICAS}

[1] AOAC-Official Methods of Analysis of the Association of Official Analytical Chemists. $16^{\mathrm{a}}$ ed. v. 2. Food Composition; Additives; natural Contaminants, seção 33. 1997.

[2] AOAC-Official Methods of Analysis of the Association of Official Analytical Chemists. $16^{\mathrm{a}}$ ed. v. 1. Seção 11. 1998.

[3] ATHERTON, H. V. \& NEWLANDER, J. A. Chemistry and Testing of Dairy Products. 4ed. Westport, AVI. 396 p. 1981.

[4] BASTIAN, E. D.; COLLINGE, S. K. \& ERNESTON, C. A. Ultrafiltration: Partionig of Milk Constituints Into Permeate and Retentate. Journal of Dairy Science. v. 74. p. 24232434. 1991.

[5] CHERYAN, M. Ultrafiltration Handbook. Technomic Publishg Company Inc. Lancaster, Pennsylvania. 375p. 1986.

[6] DALGLEISH, D. G.; MOURIK, L. van \& CORREDIG, M. HeatInduced Interactions of Whey Proteins and Casein Micelles with Different Concentrations of $\alpha$-Lactoalbumin and $\beta$ - 
Lactoglobulin. Journal of Agricultural and Food Chemistry. v. 45, n. 12. p. 4806-4813. 1997.

[7] FIL IDF. International Dairy Federation 20, Brussels, Belgium, 1962.

[8] FREEMAN, N, W. \& MANGINO, M. E. Effects of ultra High Temperature Processing on Size and Appearance of Casein Micelles in Bovine Milk. Journal of Dairy Science. v. 64, p. 1772-1780. 1981.

[9] HAQUE, Z. \& KINSELLA, J. E. Interaction between heated kcasein and $\beta$-lactoglobulin: predominance of hydrophobic interactions in the inicial stages of complex formation. Journal of Dairy Research. v. 55. p. 67-80. 1988.

[10] HASHIZUME, K. \& SATO, T. Gel-Forming Characteristics of Milks Proteins. 1. Effect of Heat Treatment. Journal of Dairy Science, v. 71, p. 1439-1446. 1988.

[11] JEURNINK, T. J. M. Fouling of Heat exchangers in relation to the serum protein concentration in milk. Milchwissenschaft. v. 50 , n. 5 , p. $257-260.1995$

[12] KESSLER, H. G.; GERNEDEL, C. \& NAKANISHI, K. The effect of low molecular weight milk constituents on the flux in ultrafiltration. Milchwissenschaft. v. 37, n. 10, p. 584587. 1982

[13] LANARA - Laboratório Nacional de Referência Animal. Métodos Analíticos Oficiais para Controle de Produtos de Origem Animal e seus Ingredientes II. Métodos Físico-Químicos. Cap. XVIII-1, metodologia 3. 1981.

[14] LEWIS, M. J. Concentration of Proteins by ultrafiltration. Developments in Food Protein. Ed. Hudson, J. F. London \& New York, Applied Science Publishers. v. 1, cap. 3. p. 91-130. 1982.

[15] MAHAUT, M.; KOROLKCZUK, J.; PANNETIER, R. \& MAUBOIS, J. L. Eléments de fabrication de fromage de type patê molle de lait de chèvre à caractère lactique par ultrafiltration de lait acidifié et coagulé. Techinique Latère \& Marketing. Julho-agosto, n. 1011. p. 24-28. 1986.

[16] MARSHALL, A. D. \& DAUFIN, G. Phusico-Chemical Aspects of Membrane Fouling by Dairy Fluids. Fouling and Cleaning in Pressure Driven Membranes Processes. International Dairy Federation. p. 8-29. 1995.

[17] MONTGOMERY, D. C. Design and Analyses of Experiments. $3^{\text {a }}$ edição. 1991.

[18] MOTTAR, J.; BASSIER, A.; JONIAU, M. \& BAERT, J. Effect of Heat-Induced Association of Whey Proteins and Casein
Micelles on Yogurt Texture. Journal of dairy Science. v. 72, p. 2247-2256. 1989.

[19] MULVIHILL, D. M. \& DONOVAN, M. Whey Proteins and their Thermal Denaturation - A Review. Irish Journal of Food Science and Technology, v. 11, p. 43-75. 1987.

[20] PARNELL-CLUNIES, E.; KAKUDA, Y.; de MAN, J. M. \& CAZZOLA, F. Gelation Profiles of Yogurt as Affected by Treatment of Milk. Journal of Dairy Science, v. 71. p. 582-588. 1988.

[21] PARRY, R. M. Jr. Milk coagulation and protein denaturation. Fundamentals of Dairy Chemistry. $2^{\text {nd }}$ edição. The AVI Publishing Company, INC. Fundamentals of Dairy Chemistry. Ed. Weeb, B. H.; Johson, A. H. \& Alford, J. A. p. 603-661. 1978.

[22] PATEL, R. S.; REUTER, H. \& PROKOPEC, D. Production of quarg by ultrafiltration. Journal of the Society of Dairy Technology. v. 39, n. 1. p. 27-31. 1986.

[23] POULIOT, Y. \& JELEN, P. Pretreatments of Dairy Fluids to Minimize Long-Therm Membrane Fouling. Fouling and Cleaning in Pressure Driven Membrane Processes. International Dairy Federation, Brussels, Belgium. p. 8090. 1995.

[24] RAMACHANDRA, H. G.; LEWIS, M. J. \& GRANDISON, A. S.. Effect of Soluble Calcium of Milk on Fouling of Ultrafiltration Membranes. Journal of Science and Food Agriculture. v. 65. p. 249-256. 1994.

[25] RENNER, E. \& ABD EL-SALAM, M. H. Application of Ultrafiltration in the Dairy Industry. Elsevier Applied Science. London \& New York. p. 284-288. 1991.

[26] SACHDEVA, S; REUTER, H; PROKOPEK, D \& KLOBES, $H$. Aspects of Quarg Making by Ultrafiltration of Coagulated Milk. Cultured Dairy Journal. v. 28, n. 4, november. p. 21-26. 1993.

[27] SCHARAML, J. E.; SPIEGEL, T. \& KESSLER, H. G. Effects of composition and concentration of dairy liquids on fouling structure. Milchwissenschaft. v. 51, n. 11. p. 607-609. 1996

[28] VÉTIER, C.; BENNASAR, M. \& LA FUENTE, B. T. de. Study of the fouling of a mineral microfiltration membrane using scanning electron microscopy and physicochemical analyses in the processing of milk. Journal of Dairy Research, v. 55, n. 3. p. 381-400. 1988. 